\title{
A “GUERRA CIVIL”À LUZ DO DIREITO INTERNACIONAL DOS CONFLITOS ARMADOS
}

Recebido: 02.04.2020

\author{
Ana Paula Martins Amaral \\ Pós-Doutora pela Universidade Federal de Santa \\ Catarina. Professora permanente da UFMS. \\ EMAIL: anapaulamartinsa@yahoo.com.br \\ LATTES: http:/ / lattes.cnpq.br/2909148996309717 \\ ORCID: http://orcid.org/0000-0001-8103-3530
}

\author{
Aprovado: 03.05.2020
}

\author{
Luiz Rosado Costa \\ Mestre em Direito pela Universidade Federal de \\ Mato Grosso do Sul. \\ E-MAIL: luizrosadocosta@gmail.com \\ LATTES: http://lattes.cnpq.br/6850285493583530 \\ ORCID: http://orcid.org/0000-0002-0851-8459
}

\begin{abstract}
RESUMO: Atualmente, os conflitos armados internos (guerras civis) são mais recorrentes que o conflito direto entre Estados, assim, o presente trabalho tem como objeto analisar a aplicabilidade das normas e princípios de Direito Internacional dos Conflitos Armados para limitação aos meios e métodos de combate e proteção às vítimas, aos conflitos armados não internacionais. Este estudo, descritivo e exploratório, por meio dos métodos bibliográfico e documental, analisa de que maneira as normas e princípios de Direito Internacional dos Conflitos Armados são (ou deveriam ser) aplicadas a esse tipo de conflito e apontar alternativas jurídicas tendentes a preencher eventuais lacunas normativas sobre este tipo de conflito armado.
\end{abstract}

PALAVRAS-CHAVE: Conflitos Armados não internacionais. Convenções de Genebra. Guerra civil. Direito Internacional dos Conflitos Armados.

\begin{abstract}
Currently, internal armed conflicts (civil wars) are much more recurrent than direct conflict between states, so the present work aims to analyze the applicability of the norms and principles of international law of armed conflicts to limit the means and methods of combat and protection to victims, non-international armed conflicts. This descriptive and exploratory study, through bibliographic and documentary methods, analyzes how the norms and principles of international law of armed conflicts are (or should be) applied to this type of conflict and point out legal alternatives that tend to fill any normative gaps on this issue.
\end{abstract}

KEYWORDS: Non-international armed conflicts. Geneva Conventions. Civil war. International Law of Armed Conflicts.

SUMÁRIO: 1 Introdução 2 O Contexto Atual dos Conflitos Armados 2.1 Marcos legais sobre os conflitos armados não-internacionais 2.2 As convenções de Genebra de 19492.3 Os protocolos adicionais 3 As Pessoas Privadas de Liberdade em Conflitos Armados Internos 4 Crimes Praticados em Contexto de Conflito Armado Interno: Punição Pelo Tribunal Penal Internacional 5 Consideraçoes Finais 6 Referências

\section{Introdução}

O presente trabalho tem como objetivo analisar as condicionantes jurídicas que decorrem das especificidades de conflitos armados internos, analisando-se a (in) 
aplicabilidade das normas e princípios de Direito Internacional dos Conflitos Armados a este tipo de conflito.

Desde o fim da Guerra Fria, representado pela queda do Muro de Berlim e o fim da União das Repúblicas Socialistas Soviéticas, ocorridos em 1989 e 191, respectivamente, observa-se no contexto global o aumento de conflitos internos associados ao nacionalismo, ao fundamentalismo religioso, às disputas étnicas e ao fortalecimento de ameaças como o terrorismo, o tráfico de drogas e o crime organizado.

Assim, reveste-se de importância o estudo sobre a maneira que as normas de Direito Internacional dos Conflitos Armados são (ou deveriam ser) aplicadas a esse tipo de conflito, atualmente mais recorrente que o conflito direto entre Estados.

Quanto à metodologia, toma-se como base para classificação da pesquisa o critério proposto por Vergara (1998) que a qualifica quanto aos fins e quanto aos meios.

Quanto aos fins, a pesquisa será descritiva e exploratória: Descritiva pois pretende expor os marcos legais que regulam, à luz do Direito Internacional dos Conflitos Armados, os conflitos armados não internacionais. Exploratória porque visa a sondar alternativas jurídicas tendentes preencher possíveis lacunas que possam despontar nesta categoria de conflito armado. Quanto aos meios a pesquisa será bibliográfica e documental. Bibliográfica pois se recorrerá ao uso de textos com contribuições dos autores em estudos analíticos publicados em livros, artigos, teses e dissertações. Documental porque será feito igualmente uso de textos sem tratamento analítico como documentos legais nacionais e internacionais.

O Brasil está há um longo período sem guerras civis em seu território, mas historicamente já teve algumas como, por exemplo, a Guerra dos Farrapos e a Guerra do Contestado. Há, assim, no contexto de ser o Brasil um Estado Democrático de Direito - que tem por fundamento a dignidade da pessoa humana (art. 1ㅇ, III, da CF) - a necessidade de a Força Terrestre, ao mesmo tempo em que se prepara para a defesa da Pátria e à garantia dos poderes constitucionais, estar preparada para atuar dentro dos limites impostos pelo ordenamento jurídico internacional de que é signatário.

\section{Contexto Atual dos Conflitos Armados}

O contexto dos conflitos armados hoje se mostra bem diferente do apresentado no início e metade do século $X X$, quando ainda era comum a guerra entre Estados. Conforme observam Cepaluni e Mendonça (2006, p, 205):

Os "novos conflitos" são bastante diferentes dos tradicionais. $\mathrm{Na}$ verdade, argumenta-se que os "antigos conflitos" entre Estados soberanos são improváveis por pelo menos três motivos. Primeiro, a invenção de armas nucleares tornou-os irracionais. Uma pequena quantidade de armamento nuclear poderia destruir nações inteiras e prejudicar grande parte do planeta por causa dos efeitos da radiação. Em segundo lugar, o amplo acesso à informação no Ocidente tornou mais difícil a ascensão de líderes como Hitler e Mussolini, capazes de mobilizar todo um país em prol de anseios expansionistas. Por último, não há mais os grandes contenciosos econômicos capazes de provocar guerras entre Estados. As instituições internacionais e seus fóruns de solução de controvérsias criaram mecanismos para solução de conflitos por 
meio da diplomacia, da negociação, sendo desnecessário, por exemplo, o lançamento de mísseis para reduzir taxas de importação.

Diante deste novo contexto global torna-se necessário o estudo das normas aplicáveis aos "novos conflitos", i.e., aos conflitos armados internos e guerras civis a fim de que o Exército Brasileiro esteja apto a atuar ou intervir nesta modalidade de conflitos dentro da legalidade.

\subsection{Marcos legais sobre os conflitos armados não-internacionais}

O Direito Internacional dos Conflitos Armados ${ }^{1}$ é ramo do Direito autônomo em relação ao Direito Internacional dos Direitos Humanos, mas com ele converge no objetivo de proteção à pessoa humana através de instrumentos internacionais de proteção que estejam acima do ordenamento jurídico interno dos Estados ${ }^{2}$.

A formação e o reconhecimento de um direito aplicável durante os conflitos armados (jus in bello) para a proteção às vítimas por meio da limitação dos meios e métodos de combate e da vedação de ataques a alvos civis e àqueles que não mais participam das hostilidades, deu-se de forma gradual ao longo da História, como respostas às atrocidades cometidas durantes os conflitos armados internacionais, em sucessivas tentativas para "humanizar" os combates e reduzir, o quanto possível, seus horrores ${ }^{3}$ :

É verdade que a guerra deve ser prevenida e punida, mas tal não nos pode eximir de tratar dos males que ela causa, devendo o nosso objectivo consistir em salvaguardar a humanidade da realidade da guerra. É precisamente este o objectivo (sic) do Direito Internacional Humanitário (DIH): em nome dos princípios de humanidade e de dignidade reconhecidos por todas as formas de civilização, proteger a pessoa que se encontra numa situação perigosa devido à violência causada pela guerra (DEYRA, 2001, p. 11-2).

Embora inicialmente pensado para o contexto de conflitos armados internacionais, o Direito Internacional dos Conflitos Armados também se aplica ao contexto dos conflitos armados internos, conforme será demonstrado a seguir.

\footnotetext{
${ }^{1}$ Este ramo do Direito é chamado de Direito Internacional Humanitário por alguns autores e pelo Comitê Internacional da Cruz Vermelha.

${ }^{2}$ No plano normativo a interação entre o Direito Internacional dos Conflitos Armados e os Direitos Internacional dos Direitos Humanos é manifesta, por exemplo o art. 3을 das 4 Convenções de Genebra de 1949 proclama direitos humanos básicos, aplicáveis tanto a tempos de conflitos armados como de paz.

${ }^{3}$ A primeira Convenção de Genebra, de 1863 foi, por exemplo, uma reação aos horrores da Guerra da Crimeia (1853-1856), narrados por Henry Dunant, fundador do Movimento Internacional da Cruz Vermelha, em seu livro Lembrança de Solferino. A ela sucederam-se as Convenções de 1906, 1929 e 1949, esta última ainda no calor da Segunda Guerra Mundial.
} 


\subsection{As convenções de Genebra de 1949}

A preocupação com a proteção dos direitos dos não combatentes para que não houvesse repetição de violações massivas aos mesmos resultaram em um consenso na comunidade internacional: atualmente, 189 países são partícipes das Convenções de Genebra, 159 do Protocolo I e 152 do Protocolo II.

As quatro convenções de Genebra de 1949, de 12 de agosto de 1949, e seus protocolos adicionais de 1977 formam o atual "Direito de Genebra" que tem como objetivo proteger as vítimas de conflitos armados: a) membros das Forças Armadas fora de combate; b) feridos; c) doentes; d) náufragos; e) prisioneiros de guerra; f) população civil; e g) todas as pessoas que não participem ou tenham deixado de participar das hostilidades.

Talvez por ainda estar fresca na memória de seus redatores a tragédia da Guerra Civil Espanhola (1936-1939), as Quatro Convenções de Genebra de 1949, expressou a consciência da relevância de uma regulamentação também para os conflitos armados não internacionais em seu art. $3^{\circ}$, comum:

"A preocupação com esta categoria de conflitos inspirou o dispositivo comum às quatro Convenções de Genebra de 1949, sob a forma do artigo 3, onde se prevê expressamente a aplicabilidade do direito humanitário na situação de conflitos armados que não apresentem um caráter internacional e que surja no território de uma das Partes contratantes" (SWINARSKI, 1996, p. 24).

O artigo 3으, comum às quatro Convenções de Genebra, marcou uma ruptura: pela primeira vez, um documento internacional abrange expressamente as situações de conflitos armados não internacionais.

Em essência: determina o tratamento humano para todos os indivíduos em poder do inimigo, sem nenhuma distinção adversa; determina que os feridos, enfermos e náufragos sejam recolhidos e tratados; outorga ao Comitê Internacional da Cruz Vermelha (CICV) o direito de oferecer seus serviços às partes em conflito; insta as partes em conflito para pôr em vigor, mediante os chamados acordos especiais, a totalidade ou as partes das Convenções de Genebra; reconhece que a aplicação dessas disposições não afeta o estatuto jurídico das partes em conflito.

Insta salientar que a expressão "guerra civil" embora seja de uso corrente para designar conflitos armados internos nos quais as forças de um Estado combate contra forças insurgentes em seu território, não aparece em nenhum documento de Direito Internacional dos Conflitos Armados.

O art. 3o comum às quatro Convenções de Genebra, por exemplo, usa a expressão "conflito armado sem caráter internacional".

Considerando-se que a maioria dos conflitos armados atuais é de índole não internacional, a aplicação do artigo 3o comum é da maior importância, sendo necessário respeitá-lo completamente.

Tamanha foi a importância atribuída ao artigo 3ำ pelos responsáveis pela redação das Convenções de Genebra de 1949 que sua redação foi repetida nas quatro Convenções, tentando-se, assim, reduzir a probabilidade de sua não ratificação: p.e., se um Estado ratificasse apenas uma das Convenções de Genebra. Assim, basta que o Estado seja 
signatário de quaisquer das Convenções de Genebra de 1949 para que esteja submetido à norma do art. 3ㅇ comum.

Antes do advento do art. 3 Comum às Convenções de Genebra, o único dispositivo de Direito Internacional dos Conflitos Armados aplicável, por analogia, aos conflitos armados não internacionais era a alcunhada Cláusula Martens, inserida no preâmbulo da IV Convenção de Haia de 1907, e que àquela época já previa o uso da analogia para ampliar o alcance protetivo do Direito Internacional dos Conflitos Armados:

Até que um código mais completo de leis de guerra seja editado, as Altas Partes Contratantes consideram este expediente para declarar que em casos não inclusos nas Regulações adotadas por elas, os habitantes e combatentes permanecem sob a proteção dos princípios do direito das nações, como resultado dos costumes estabelecidos entre as nações civilizadas, das regras de humanidade e dos ditames da consciência pública. (YALE LAW SCHOOL, 2011, tradução nossa).

Conforme dispõe a Cláusula Martens, o fato de uma atividade bélica não ser especificamente regulada não quer dizer que esta não esteja sujeita a qualquer limitação, o que decorre do princípio da humanidade e, para Direito Internacional dos Conflitos Armados, são mais relevantes os efeitos que a forma como conflito armado se desenrola.

\subsection{Os protocolos adicionais}

As quatro convenções visavam a dar respostas aos problemas humanitários da forma que eram apresentados em 1949, ainda no calor da Segunda Guerra Mundial. Em face do novo contexto internacional de Guerra Fria e aumento dos conflitos armados nãointernacionais, mostrou-se necessária a adaptação do Direito de Genebra aos novos tempos:

O considerável aumento de conflitos bélicos não internacionais, assim como o desenvolvimento de novos meios de guerra, junto com a profunda transformação da estrutura da comunidade internacional tornaram indispensável a adaptação do Direito Humanitário para que este possa continuar cumprindo adequadamente suas finalidades de proteção (SWINARSKI, 1990, p. 38).

Por estas razões convocou-se em 1974 uma conferência diplomática que elaborou dois tratados complementares às Convenções de Genebra, os Protocolos Adicionais I e II de 8 de junho de 1977:

Estava fora de questão modificar as Convenções de Genebra, já que importava salvaguardar o que tinha sido previamente adquirido. É por esta razão que os Protocolos Adicionais, tal como o seu adjectivo indica, vieram completar, e não substituir, as Convenções de Genebra que, no caso das três primeiras, vieram 
por sua vez substituir as convenções anteriormente adoptadas na mesma matéria (DEYRA, 2001, p. 21).

Insta salientar que Os Protocolos não visam a substituir as Convenções, mas complementá-las., assim, o Protocolo I complementa e desenvolve as disposições sobre os conflitos armados internacionais. O Protocolo Il é aplicável na situação de conflito armado não internacional e complementa o art. 3o comum às Convenções de Genebra de 1949. Cahen $(2009$, p. 79) destaca que até meados do século XX, ainda seguindo uma concepção estrita de soberania nacional, os Estados resistiram a instauração de um Direito Internacional Humanitário aplicável a situações de guerra civil.

Assim, ante esta circunstância de resistência dos Estados, houve uma proteção mínima às pessoas no artigo 3o comum, que foi ampliada apenas em 1977 com o Protocolo Adicional II ${ }^{4}$ às Convenções de Genebra de 1949.

Destaque-se, neste sentido, que o Direito Internacional dos Conflitos Armados:

Não afeta a soberania de um Estado ou o direito de um governo de terminar com a rebelião com suas forças armadas e julgar os insurgentes com suas próprias leis. (LAWAND, 2012).

Kolb e Hyde (2008, p. 69) pontuam que: “As distinções na proteção legal conferida aos conflitos armados internacionais e não-internacionais tornaram-se progressivamente injustificadas" ${ }^{5}$.

Caso o que haja no interior de um Estado seja a situação de tensões internas e distúrbios interiores, que se caracterizam por um nível menor de violência, não há aplicação direta do art. 3o comum às Convenções de Genebra de 1949 e do Protocolo Adicional II de 1977, por falta de previsão normativa ${ }^{6}$ mas, como destaca Swinarski (1991, p. 31):

Logicamente, os princípios fundamentais das Convenções de Genebra podem servir de padrões de procedimentos jurídicos ou inspirar a elaboração das normas aplicáveis, de tal modo que se justifica falar da aplicabilidade por analogia, senão da aplicabilidade indireta do direito internacional humanitário em ambas as situações.

Aplica-se, pois, a analogia quando esta oferecer uma maior proteção às pessoas envolvidas no contexto de um conflito armado, seja interno ou internacional.

\footnotetext{
${ }^{4}$ O Protocolo Adicional $\mathrm{n}^{\circ} 2$ foi promulgado no Brasil por meio do Decreto $\mathrm{n}^{\circ} \mathbf{8 4 9}$, de 25 de junho de 1993 (BRASIL, 1993).

${ }^{5}$ Tradução livre de: "The distictions in legal protections afforded to international and noninternational armed conflicted were progressively felt to be unjustified" (KOLB; HYDE, 2008, p. $69)$.

${ }^{6}$ O Protocolo Adicional II de 1977 dispõe em seu art. $1^{\circ}, 2$, que: "2 - O presente Protocolo não se aplica às situações de tensão e de perturbação internas, tais como motins, atos de violência isolados e esporádicos e outros atos análogos, que não são considerados como conflitos armados" (BRASIL, 1993).
} 


\section{As Pessoas Privadas de Liberdade em Conflitos Armados Internos}

A 3a Convenção de Genebra de 1949 atribui o status especial de prisioneiro de guerra somente aos combatentes inimigos capturados em conflitos armados internacionais:

No conflito armado não internacional, o status de combatente ou de prisioneiro de guerra não é fornecido porque os Estados não desejam que os membros dos grupos armados de oposição estejam imunes de serem processados de acordo com o direito doméstico, pelo fato de se sublevarem armados. (CICV, 2005).

Confirmando isso e para evitar confusões terminológicas, o Protocolo Adicional II, em seu artigo 5, usa a expressão "pessoas privadas de liberdade" no lugar de "prisioneiros".

Desta maneira, os rebeldes/insurgentes que forem capturados poderão, à luz do Direito Internacional dos Conflitos Armados, ser processados e julgados por pegarem em armas contra o Estado. No Brasil, por exemplo, essa possibilidade é prevista na Constituição Federal de 1988 quando prevê em seu art. 5ㅇ, XLIV que: "XLIV - constitui crime inafiançável e imprescritível a ação de grupos armados, civis ou militares, contra a ordem constitucional e o Estado Democrático" (BRASIL, 1988).

Nesse caso, o Protocolo Adicional II estabelece uma série de garantias ao rebelde que seja julgado pelo Estado:

As sentenças somente poderão ser pronunciadas por tribunais que ofereçam garantias essenciais de independência e imparcialidade: o acusado será informado sem demora dos detalhes do crime de que é acusado, com exclusão da responsabilidade coletiva e da condenação por ato ou omissão que, à época em que foi cometido, não constituía crime, presunção de inocência, julgamento na presença do acusado, ausência de coação para se obter confissões, informação do direito de interpor recursos. Não se imporá a pena de morte àqueles que, à época em que foi cometida a infração, contavam com menos de dezoito anos de idade, ou às mulheres grávidas ou mães de crianças pequenas (CICV, 2000, p. 54).

As pessoas privadas de liberdade em decorrência do conflito armado não internacional, embora não tenham o status de prisioneiros de guerra, têm, segundo o Protocolo Adicional II, garantidos todos os direitos relativos a assistência médica, alimentação, higiene, segurança, socorro, prática religiosa e condições de trabalho.

O Protocolo Adicional II prevê ainda que os homens deverão permanecer separados das mulheres, salvo se da mesma família. 


\section{Crimes Praticados em Contexto de Conflito Armado Interno: Punição pelo Tribunal Penal Internacional}

O Tribunal Penal Internacional (TPI), criado pelo Estatuto de Roma ${ }^{7}$, é um Tribunal independente, de caráter permanente e vinculado ao sistema das Nações Unidas, que tem competência para os seguintes crimes: a) $\mathrm{O}$ crime de genocídio; b) Crimes contra a humanidade; c) Crimes de guerra; d) $\mathrm{O}$ crime de agressão. Neste sentido, destaca-se que o:

Tribunal Penal Internacional é considerado uma conquista para os Estados signatários do Estatuto de Roma na medida em que concretiza o ideal de realização de justiça internacional. Sua história, ou melhor, as propostas que lhe antecederam, revelam o interesse continuado na criação de órgão que pudesse julgar e punir crimes que desestabilizem valores da comunidade mundial (MINAHIM, SPÍNDOLA, 2018, p. 200).

Ao considerar que para as vítimas civis, não faz diferença se o ataque é de forças combatendo em conflito armado internacional ou interno, o Tribunal Penal Internacional previu crimes específicos para a situação de conflito armado não-nternacional em seu ar. 8, (2), (e), que assim dispõe:

Artigo $8^{\circ}$

Crimes de Guerra

(...)

e) As outras violações graves das leis e costumes aplicáveis aos conflitos armados que não têm caráter internacional, no quadro do direito internacional (BRASIL, 2002, negrito nosso).

Conforme já mencionado, os Estados podem submeter a julgamento os insurgentes que pegaram em armas contra si e no caso de crimes de guerra, caso não o faça, será atraída a competência do Tribunal Penal Internacional:

A atuação do Tribunal Penal Internacional assenta-se sobre alguns princípios fundamentais, sendo talvez o mais importante o da complementariedade. De acordo com o mesmo, a Corte somente atua se o Estado que tem jurisdição sobre determinado caso não iniciou o devido processo ou, se o fez, agiu com o intuito de subtrair o acusado à justiça ou de mitigar-lhe a sanção. Este postulado, à primeira vista, parece chocar-se com os fins colimados no Tratado de Roma, mas justifica-se porque compete em primeiro lugar aos Estados o dever de reprimir os crimes capitulados no Estatuto do Tribunal, até para que a repressão se faça de modo mais eficaz. A Corte, pois, atua apenas

\footnotetext{
${ }^{7}$ O Estatuto de Roma do Tribunal Penal Internacional foi promulgado no Brasil por meio do Decreto oㅜ 4.388, de 25 de setembro de 2002.
} 
subsidiariamente, agindo sobretudo na hipótese em que ocorre "a falência das instituições nacionais (LEWANDOWSKI, 2002).

Desta maneira, as graves violações ao Direito Internacional Humaniário no contexto de um conflito armado interno, serão consideradas como crime de guerra nos termos do Estatuto de Roma e poderão ser julgadas pelo Tribunal Penal Internacional, como ocorreu, por exemplo, no julgamento de Thomas Lubanga Dyilo ${ }^{8}$. condenado, em 10 de Julho de $\underline{2012}$ a um total de 14 anos de prisão pelo recrutamento de crianças para lutar na guerra civil de Ituri, na República Democrática do Congo, entre 2002 e 2003.

\section{Consideraçoes Finais}

Após o fim da Guerra Fria, a partir da década de 1990, observa-se uma redução no número de conflitos armados diretos entre Estados soberanos e um aumento significativo de conflitos internos associados ao nacionalismo, ao fundamentalismo religioso, às disputas étnicas e ao fortalecimento de ameaças como o terrorismo, o tráfico de drogas e o crime organizado. Assim, reveste-se de importância o estudo das normas de Direito Internacional dos Conflitos Armados aplicáveis no contexto de um conflito armado não internacional.

Neste sentido verificou-se que 0 art. 30 comum às quatro Convenções de Genebra de 1949 traz uma primeira regulamentação dos conflitos armados não internacionais e foi complementada pelo Protocolo Adicional II, de 1977, às Convenções de Genebra. E o Brasil, como signatário de ambos documentos internacionais lhes deve observância caso venha a se envolver em uma situação de guerra civil ou conflito armado não internacional.

Apesar da resistência inicial dos Estados a uma regulamentação dos conflitos armados internos, sob alegação de que violariam sua soberania, verificou-se que a regulamentação destes conflitos pelo Direito Internacional dos Conflitos Armados não a viola, pois não veda que os Estados submetam os insurgentes, que não possuem o status especial de prisioneiros de guerra, a julgamento por suas autoridades.

Por fim, as graves violações ao Direito Internacional dos Conflitos Armados no contexto de um conflito armado interno serão consideradas como crime de guerra nos termos do Estatuto de Roma e poderão ser julgadas pelo Tribunal Penal Internacional.

\section{Referências}

BRASIL. Constituição da República Federativa do Brasil de 1988. Disponível em:<http://www.planalto.gov.br/ccivil_03/Constituicao/Constituicao.htm>. Acesso em: 10 maio 2019.

BRASIL. Decreto no $\mathbf{8 4 9}$, de 25 de junho de 1993 . Disponível em: <http://www.planalto.gov.br/ccivil_03/decreto/1990-1994/D0849.htm>.Acesso em: 31 jul. 2019.

\footnotetext{
${ }^{8}$ Esta foi a primeira condenação proferida pelo Tribunal Penal Internacional e foi feita com base em fatos ocorridos no contexto de uma guerra civil.
} 
CAHEN, Daniel. Principios, mecanismos y instrumentos a tener em cuenta em el caso colombiano. In: GUEVARA, Sonia Beltrán de. Colombia: conflito y derecho internacional humanitário. Madri: Ediciones GPS, 2009.

CEPALUNI, Gabriel; MENDONÇA, Filipe. As razões da guerra civil: necessidade, crença e ganância. Revista Sociologia e Política, Curitiba, 27, p., nov. 2006

CICV. Normas fundamentais das Convenções de Genebra e de seus Protocolos Adicionais. Genebra: CICV, 2000.

DEYRA, Michel. Direito internacional humanitário. Lisboa: Gabinete de Documentação e Direito Comparado da PGR, 2001.

KOLB, Robert; HYDE, Richard. An introduction to the Internatonal Law of Armed conflicts. Oxford: Hart Publishing, 2008.

LAWARD,Kathleen. Conflitos internos ou outras situações de violência qual a diferença para as vítimas? Disponível em: <https://www.icrc.org/pt/doc/reso urces/documents/interview/2012/12-10-niac-non-international-armed-conflict.htm>.

Acesso em: 30 jul. 2019.

LEWANDOWSKI, Ricardo Enrique. O Tribunal Penal Internacional: de uma cultura de impunidade para uma cultura de responsabilidade. Estudos avançados. vol.16 no.45 São Paulo. Maio /Ago. 2002. Disponível: <http://www.scielo.br/scielo.php?pid=S0103$40142002000200012 \&$ script=sci_arttext>. Acesso em: 26 jul. 2019.

MINAHIM, Maria Auxiliadora de Almeida; SPÍNOLA, Luíza Moura Costa. Julgamento de uma ex-criança-soldado pelo tribunal penal internacional: o caso dominic ongwen. In: Revista do Programa de Pós-Graduação em Direito da UFBA, V. 28, N. 01, pp 197-225, Jan - Jun 2018.

SWINARSKI, Christophe. A norma e a guerra. Porto Alegre: Sérgio Antonio Fabris, 1991. SWINARSKI, Christophe. Direito internacional humanitário como sistema de proteção internacional da pessoa humana. São Paulo: Revista dos Tribunais, 1990.

SWINARSKI, Christophe. Introdução ao Direito Internacional Humanitário. Brasília: Comitê Internacional da Cruz Vermelha, 1996.

YALE LAW SCHOOL. The Avalon Project - documents in Law, History and Diplomacy._Disponível_em:_<http://avalon.law.yale.edu/subject_menus/lawwar.asp>. Acesso em: 28 fev 2014.

VERGARA, Sylvia Constant. Projetos e relatórios de pesquisa em administração. $2 \underline{a}$ ed. São Paulo: Atlas, 1998. 